\title{
Graft Reaction of Styrene-acrylonitrile onto Metallocene-Based Polyethylene-Octene Elastomer and its Toughening Effect on SAN
}

\author{
By Yin-huan LI, Lian-shi WANG, ${ }^{*}$ Jing-qi DAI, and An-qiang ZHANG
}

\begin{abstract}
Metallocene-Based Polyethylene-Octene-graft-styrene/acrylonitrile (POE- $g$-SAN) was synthesized by grafting styrene (St) and acrylonitrile (An) onto POE elastomer. The reaction was carried out in toluene using benzoyl peroxide as initiator at $75^{\circ} \mathrm{C}$. Various weight ratios of monomers, weight ratios of POE to monomers, initiator concentration, reactant concentration, and reaction time were studied to investigate their effects on the graft copolymerization. The graft copolymer were identified and characterized by FT/IR spectroscopy and ${ }^{1} \mathrm{H}$ NMR. The chain structure of the graft copolymer was investigated by glass transition temperature using differential scanning calorimetry (DSC). The results showed that St/An was grafted on the POE chains, and the graft branches effected the crystallization of POE chains and made the melt temperature and the fusion heat be lower. In addition, according to the research on mechanical properties of the SAN/POE- $g$-SAN blend, a remarkable toughening effect of POE- $g$-SAN on SAN resin was found. By means of scanning electron microscopy (SEM), the toughening mechanism is proposed to be crazing initiation from rubber particles and shear deformation of SAN matrix.

KEY WORDS: Graft Copolymerization / Polyethylene-Octene (POE) / POE-graft-styrene/acrylonitrile (POE- $g$-SAN) / SAN/POE- $g$ SAN Blend /
\end{abstract}

Ethylene-octene copolymers (POE) produced by Du Pont Dow Elastermers Co. Ltd using a metallocene catalyst are a new family of homogeneous polyolefin polymers. It has received much attention due to its narrow molecular weight and unique uniform distribution of comonomer. ${ }^{1}$ POEs are used in modifying nonpolar polymer, such as PP. ${ }^{2}$ In addition, POEs are also functionalized or graft modified with some unsaturated low molecular compounds containing polar functional groups. In this way, these copolymers have been used in modifying polar polymer. Functional monomers that have been widely used in the modification mainly include maleic anhydride, ${ }^{3-16}$ acrylic acids, ${ }^{17,18}$ glycidyl methacrylate, ${ }^{19}$ silane $^{20}$ and undecylenic Acid. ${ }^{21}$ Such modifications are generally aimed at obtaining single monomer grafts or short length grafts that substantially change the polymer's chemical or reactive properties but not the mechanical properties. Grafting reactions can be run in a moving molten polymer in reactive mix process in the presence of peroxide initiators: such as dicumyl peroxide (DCP); tert-butyl hydroperoxide (TBHP) and benzoyl peroxide (BPO). These functional POE were used as compatibilizers agent in some kinds of polymer blend containing PET/POE, PA/POE, PP/PA6, PET/PP and $\mathrm{PP} / \mathrm{PPO}$, etc, and gave rise to strong links between the two phases.

Long-chain grafts have rarely been reported for the modification of POE. In this work, we studied the graft copolymerization of St-An and POE in solvent, and investigated the effects of various reaction conditions on the graft copolymerization. Moreover, the relation of structure and properties of the SAN/POE- $g$-SAN blend was investigated. The toughening mechanism of the blend was discussed.

\section{MATERIALS AND EXPERIMENTAL METHODS}

\section{Materials}

POE8130, produced by Du Pont Dow Elastermers Co. Ltd., USA. SAN resin, with about $30 \%$ acrylonitrile and a density of $1.08 \mathrm{~g} / \mathrm{cm}^{3}$ (350 from Kumho p\&b Chemicals, Inc. Korea). Acrylonitrile (Shanghai Chemical Reagent Corp., Shanghai, China) were purified by distillation before used. Styrene (Shanghai Chemical Reagent Corp.) was washed with 5\% aqueous sodium hydroxide solution and then with water until neutral, dried over anhydrous sodium sulfate, and distilled under vacuum before use. Benzoyl peroxide (BPO; Guangzhou Chemical Reagent Factory, Guangzhou, China) was recrystallized from ethanol. Toluene (Guangzhou Chemical Reagent Factory) is analytical purity.

\section{Graft Copolymerization Reaction}

A given amount of POE was dissolved in a certain volume of toluene in a flask equipped with a stirrer, a thermometer, a condenser, and a nitrogen gas inlet. Then a mixture of St, An and BPO was added into the flask. After charging with nitrogen, the reactions were carried out under various experimental conditions, which are shown in Table I.

The obtained product POE- $g$-SAN was precipitated in excess ethanol with stirring. The precipitate was collected by filtration and then dried to constant weight.

The pure POE- $g$-SAN graft copolymer was isolated from POE- $g$-SAN containing St-co-An by acetone in a Soxhlet extractor. The monomer conversion ratio $(\mathrm{CR})$, grafting ratio (GR), and grafting efficiency (GE) of the copolymerization were estimated using the following equations: 
Table I. Reaction Conditions for Graft Copolymerization in the Study

\begin{tabular}{ll}
\hline \multicolumn{1}{c}{ Condition } & \multicolumn{1}{c}{ Description } \\
\hline Reaction temperature $\left({ }^{\circ} \mathrm{C}\right)$ & 75 \\
Initiator concentration $(\mathrm{wt} \%)^{\mathrm{a}}$ & $1,1.5,2,2.5,3$ \\
POE/St-An (wt/wt) & $70 / 30,65 / 35,60 / 40,55 / 45,50 / 50,45 / 55,40 / 60$ \\
Styrene/Acrylonitrile (wt/wt) & $70 / 30,65 / 35,60 / 40,55 / 45,50 / 50$ \\
System concentration (wt \%) & $20,22.5,25,27.5,30$ \\
Reaction time $(\mathrm{h})$ & 20
\end{tabular}

a The concentration was based on the total weights of monomers and POE.

$$
\begin{aligned}
\mathrm{CR} & =\frac{\text { weight of monomer polymerized }}{\text { weight of monomer charged }} \\
& =\frac{\mathrm{G}-\mathrm{G} \times \mathrm{P}}{\mathrm{M}} \times 100 \% \\
\mathrm{GR} & =\frac{\text { weight of monomer grafted onto POE }}{\text { weight of POE }} \\
& =\frac{\mathrm{E}-\mathrm{G} \times \mathrm{P}}{\mathrm{G} \times \mathrm{P}} \times 100 \% \\
\mathrm{GE} & =\frac{\text { weight of monomer grafted onto POE }}{\text { weight of monomer polymerized }} \\
& =\frac{\mathrm{E}-\mathrm{G} \times \mathrm{P}}{\mathrm{G}-\mathrm{G} \times \mathrm{P}} \times 100 \% \\
\mathrm{P} & =\frac{\mathrm{D}}{\mathrm{S}} \times 100 \%
\end{aligned}
$$

Where $\mathrm{G}$ is the weight of dry sample, $\mathrm{P}$ is the weight percentage of POE in the obtained product, $\mathrm{M}$ is the weight of charged monomers, $\mathrm{E}$ is the weight of extracted dry sample, $\mathrm{D}$ is the weight of charged POE, $\mathrm{S}$ is the weight of obtained product.

\section{Characterization of Graft Product}

Fourier Transform Infrared Spectroscopy (FT/IR) was recorded on an FT/IR-800 spectrometer (Shimadzu Corporation, Japan) using compression-molded thin film samples. BrukerDRX240 ${ }^{1} \mathrm{H}$ NMR spectrometers, using Chloroform-d1 as the solvent and sealed in NMR tubes (10 mm OD) after degassing, operated at $300.1 \mathrm{MHz}$.

\section{Differential Scanning Calorimetry}

Differential Scanning Calorimetry (DSC) measurements were performed on a DSC 204 from Netzsch (Germany) Instrument under $\mathrm{N}_{2}$ atmosphere. All samples were heated from $30^{\circ} \mathrm{C}$ to $160^{\circ} \mathrm{C}$ at a rate of $10^{\circ} \mathrm{C} / \mathrm{min}$, and maintained
$160{ }^{\circ} \mathrm{C}$ for $3 \mathrm{~min}$. Then the samples were cooled down to $-110^{\circ} \mathrm{C}$ at a rate of $20^{\circ} \mathrm{C} / \mathrm{min}$, and heated to $150^{\circ} \mathrm{C}$ at a rate of $10^{\circ} \mathrm{C} / \mathrm{min}$. The melting temperature $\left(T_{\mathrm{m}}\right)$, glass transition temperature $\left(T_{\mathrm{g}}\right)$ and heat of fusion $\left(\Delta \mathrm{H}_{\mathrm{f}}\right)$ values were taken from the second heating curve.

\section{Preparation of SAN/POE- $g$-SAN Blend}

SAN and POE- $g$-SAN were dried in an oven at $80^{\circ} \mathrm{C}$ for $24 \mathrm{~h}$, and then were melt blended with a laboratory two-roll mill at $160-165^{\circ} \mathrm{C}$ for $8 \mathrm{~min}$ to obtain blends containing different POE content, followed by compression molding at $170{ }^{\circ} \mathrm{C}$. Test specimens were cut from $0.4-\mathrm{cm}$-thick plaques for mechanical properties testing. The notched Izod impact strengths were measured at room temperature according to GB1843-96. Tensile strength was measured according to GB1040-92.

\section{Phase Morphology}

The morphology of the blends was examined using a Philips XL30ESEM. The fractured surfaces of notched Izod impact tests were sputtered with gold before viewing.

\section{RESULT AND DISCUSSION}

\section{Effect of St/An Ratio}

Figure 1 shows the effect of $\mathrm{St} / \mathrm{An}$ ratio on the graft copolymerization. The reaction was carried out in toluene, with $1.5 \mathrm{wt} \%$ of the $\mathrm{BPO}, 60 / 40$ weight ratio of $\mathrm{POE} / \mathrm{St}-$ $\mathrm{An}$, and the reactant concentration of $20 \mathrm{wt} \%$ at $75^{\circ} \mathrm{C}$ for 20h. CR, GR and GE all increase with a decreasing loading of St, as well as an increasing loading of An. It is known that the An radical is about 10 times more active than the St radical because of the resonance stabilization of the benzyl ring to St, and that, the rate of copolymerization is determined mainly by the activity of radical. ${ }^{22}$ Consequently the polymerization rate increases as the loading of An increasing, as a result, $\mathrm{CR}$ increased. The increasing of GR and GE means that with the increasing of An loading, graft copolymer of POE and St-An is readily formed than the copolymer of St and An. This can be explained by the grafting mechanism of St-An onto POE, which is shown as follows: ${ }^{22,23}$

(a) Decomposition of the peroxide to primary radicals

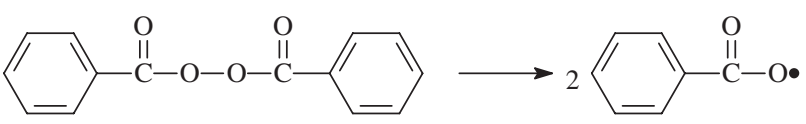

(b) Radical transfer reactions involving the primary radical and POE used

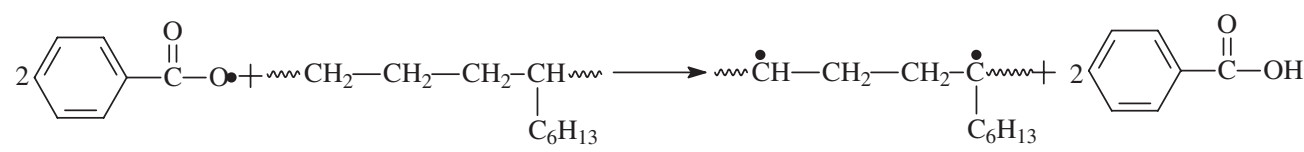


(c) Addition of monomers to primary radical or the POE macroradical

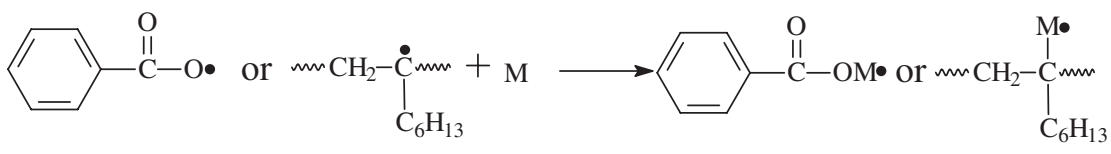

(d) Chain transfer to POE chain

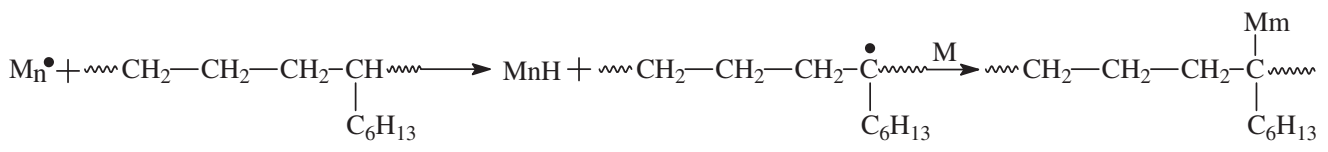

The effect of chain transfer plays an important role in graft copolymerization owing to the high POE concentration. GR and GE increase with increasing An dosage. This effect is a consequence of the greater reactivity of the An propagating radical. The chain-transfer constant for any one compound generally increases in the order of increasing radical reactivity. $^{22}$ As a result, the graft copolymer increases with increasing An propagating radical due to rising An dosage, GR and GE increased.

\section{Effect of POE/St-An Ratio}

Figure 2 shows the effect of weight ratios of POE to



Figure 1. The effect of St/An ratio on the graft copolymerization.

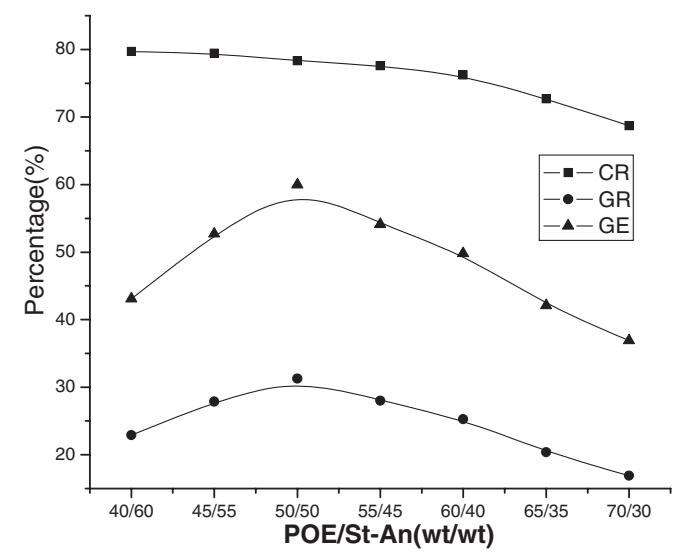

Figure 2. The effect of weight ratio of POE/St-An on the graft copolymerization. monomers that is a blend of St and An on the graft polymerization. The polymerization was performed in toluene with the initiator concentration of $1.5 \%, 55 / 45$ weight ratio of $\mathrm{St} / \mathrm{An}$, and the reactant concentration of $20 \%$ at $75^{\circ} \mathrm{C}$ for $20 \mathrm{~h}$. $\mathrm{CR}$ decreases with an increasing loading of POE, which is because that the polymerization rate decreases with decreasing monomer and free radical concentration, that is owing to the decreasing St-An percentage. Within the range of our experiment, GR and GE increase and up to a peak value at 50/50, and then decrease. For grafting reaction, it may be explained by the fact that at low St-An loading, the diffusion of monomer molecules toward the free radical sites on the POE backbone governs the grafting extent, whereas at higher concentrations of monomer, GR and GE decrease slightly as the number of freeradical sites available on the POE backbone becomes a limiting factor, ${ }^{24}$ and viscosity of the reaction system increases that the monomer molecules are difficult to diffuse to POE chains, which decreases the graft copolymerization rate. As a result, GR and GE decreased.

\section{The Effect of Initiator Concentration}

Figure 3 demonstrate the effect of initiator concentration ranging from 1.0 to $3.0 \mathrm{wt} \%$ on the graft copolymerization. The polymerization was performed in toluene with $60 / 40$ weight ratio of $\mathrm{POE} / \mathrm{St}-\mathrm{An}, 55 / 45$ weight ratio of $\mathrm{St} / \mathrm{An}$, and reactant concentration of $20 \mathrm{wt} \%$ at $75^{\circ} \mathrm{C}$ for $20 \mathrm{~h}$. CR increases with an increasing initiator concentration up to

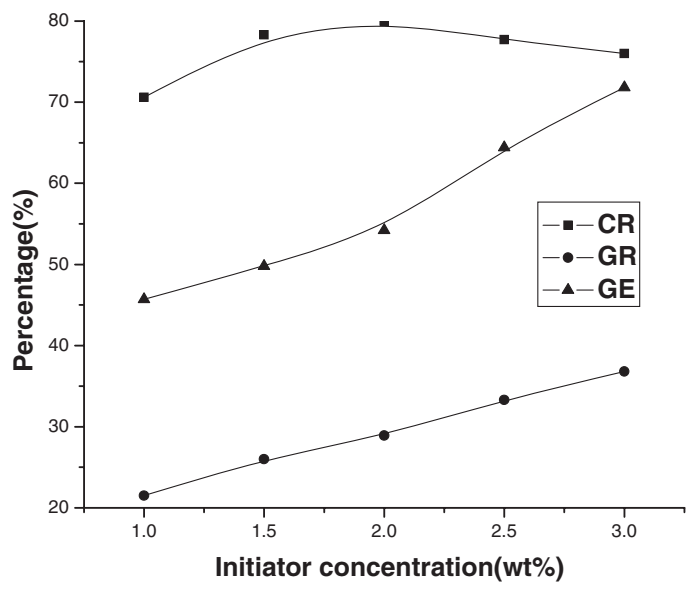

Figure 3. The effect of initiator concentration on the graft copolymerization. 


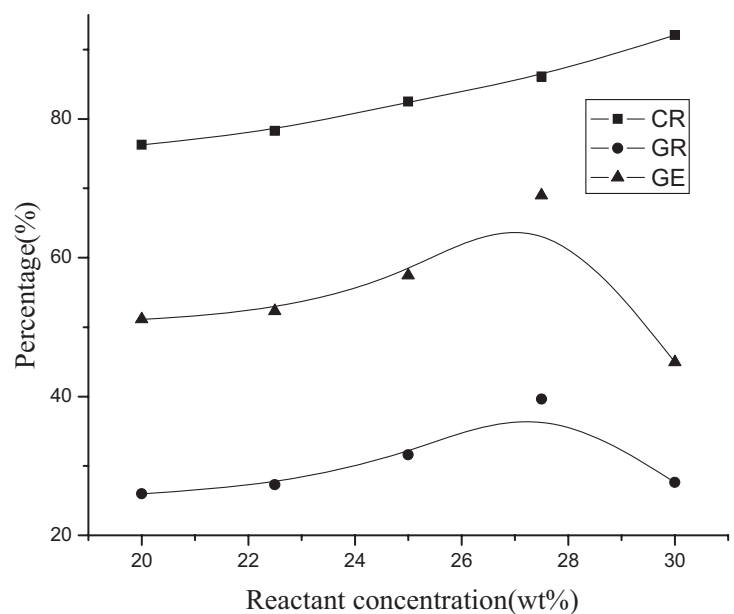

Figure 4. The effect of reactant concentration on the graft copolymerization.

$1.5 \%$, and then it decreases with further increasing initiator concentration. GR and GE increased with the increasing initiator concentration. The increasing phenomena of GR and GE can be explained by the fact that the amount of monomer radicals, propagating chain radicals and POE macroradicals increase with an increasing of initiator concentration. The more the amount of free radicals are, the monomers that grafted onto the POE are more. As a result, GR and GE increase.

\section{Effect of Reactant Concentration}

The reactant concentration is a weight ratio of POE and monomers to the whole reaction system, including POE, monomers and solvent. The effect of reactant concentration ranging from $20 \mathrm{wt} \%$ to $30 \mathrm{wt} \%$ on the graft copolymerization is shown in Figure 4 . The reaction is carried out in toluene with $1.5 \mathrm{wt} \%$ of BPO, 60/40 weight ratio of POE/St-An, and 55/45 weight ratio of $\mathrm{St} / \mathrm{An}$ at $75^{\circ} \mathrm{C}$ for $20 \mathrm{~h}$. It is obviously that $\mathrm{CR}$ increases with increasing reactant concentration. This may be explained by the fact that polymerization rate increases with reactant concentration. GR and GE increase with the increasing reactant concentration up to $27.5 \mathrm{wt} \%$, and then decreased with a further increasing reactant concentration. Polymerization rate increases with increasing of reactant concentration, however, with a further increasing of reactant concentration, the diffusion of monomer molecules and free radicals are barred severely so that the rate of graft copolymerization decreases, and the tendency of non-grafted copolymer increases, so GR and GE all decrease.

\section{Effect of Reaction Time}

The effect of reaction time on the graft copolymerization is shown in Figure 5. In this case, the reaction was carried out in toluene at $75^{\circ} \mathrm{C}$ with $60 / 40$ weight ratio of POE/St-An, 55/45 weight ratio of St/An, $1.5 \mathrm{wt} \%$ of BPO, and reactant concentration of $25 \mathrm{wt} \%$. CR increases with increasing of reaction time up to $15 \mathrm{~h}$ and then levels off. This result comes from the decreasing concentrations of monomer and initiator with increase in reaction time. GR shows essentially an identical

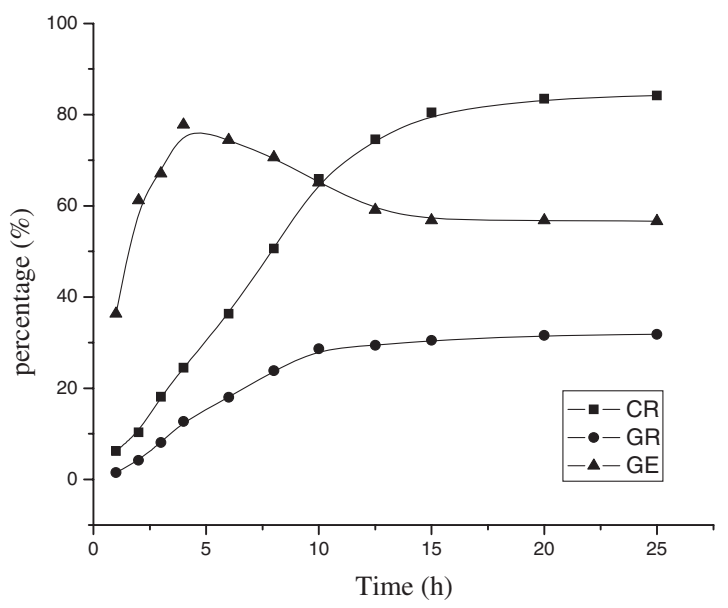

Figure 5. The effect of polymerization time on the graft copolymerization.

tendency with CR. This may be explained as being attributed to the decreases in concentrations of unreacted monomers and initiator as well as the increase in viscosity of reaction medium when the reaction proceeds. GE increased quickly in the first $4 \mathrm{~h}$, and then decreased with increasing of reaction time up to $12.5 \mathrm{~h}$. Values of GE were higher than $60.0 \%$ with the reaction time from $2 \mathrm{~h}$ to $10 \mathrm{~h}$, which shows that in this period the grafting copolymer was formed rapidly than the copolymer of St and An. This can be explained by the fact that at early reaction stage, monomer molecules and radicals are easily to diffuse to POE chains. Whereas, with increasing reaction time up to $10 \mathrm{~h}$, the viscosity of the reaction medium increases, the diffusion of monomer molecules into POE chains becomes difficult and the monomer tends to copolymerization, so GE decreases.

\section{The Characterization of POE- $g$-SAN}

The FT/IR spectra of the POE8130, SAN and the POE- $g$ SAN are illustrated in Figure 6, respectively. From the result of Figure 6, it can be seen that all characteristic peaks of POE at

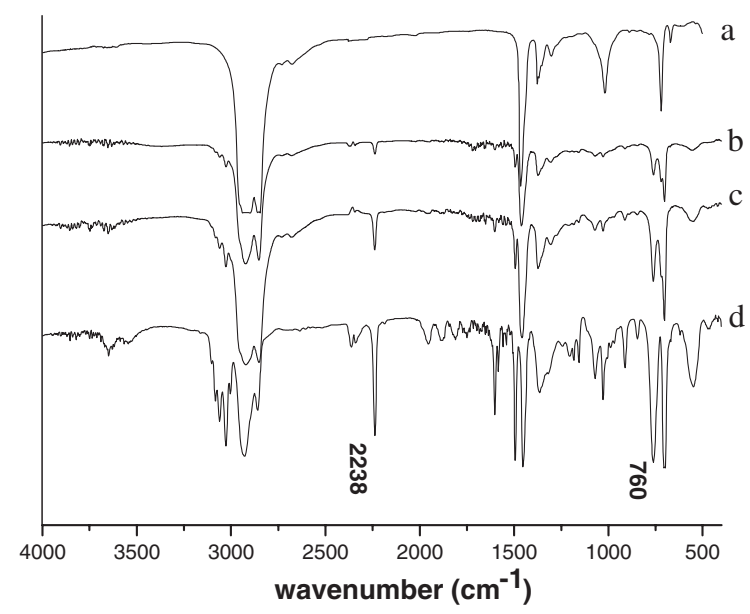

Figure 6. FT/IR spectra: (a) pure POE; (b) POE-g-SAN1, with GR of $23.4 \%$ (C) POE-g-SAN2, with GR of $39.6 \%$; (d) SAN. 


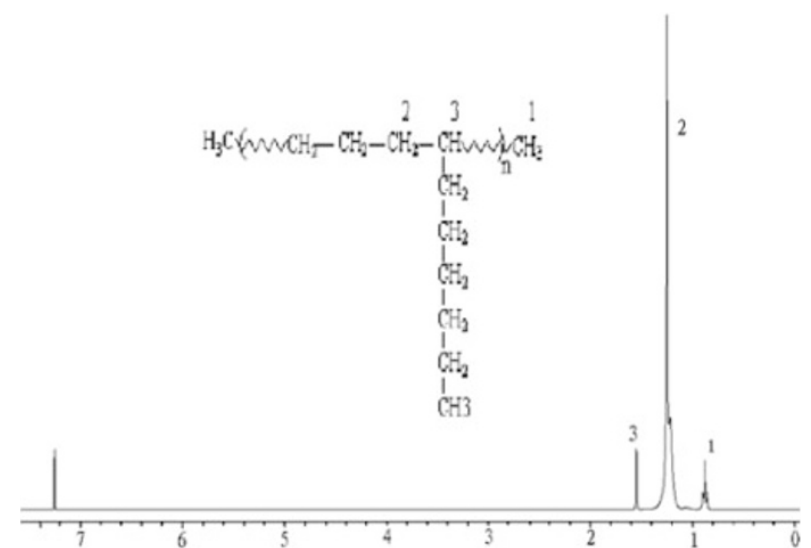

(a)

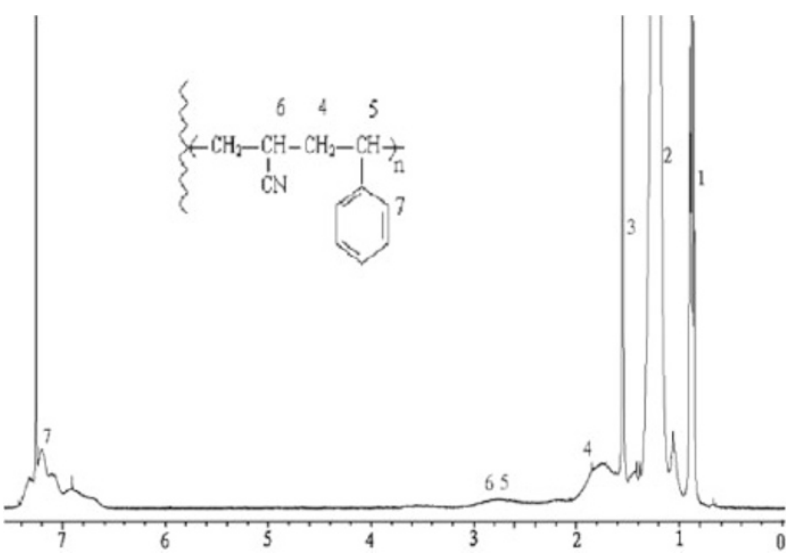

(b)

Figure 7. ${ }^{1} \mathrm{H}$ NMR spectra of pure POE and POE-g-SAN

2840-2928, 1465 , and $720 \mathrm{~cm}^{-1}$ appear in POE- $g$-SAN. It is also observed that there are two extra peaks (760 and 700 $\mathrm{cm}^{-1}$ ), which are the characteristic peaks of benzyl ring, and $\mathrm{C} \equiv \mathrm{N}$ stretching vibration absorbance at $2240 \mathrm{~cm}^{-1}$ for the POE- $g$-SAN. Similar results can be found in some proposed articles. So, it can be confirmed that St and An did be grafted onto POE. It can also be seen that the characteristic peaks of benzyl ring and $\mathrm{C} \equiv \mathrm{N}$ bond of POE- $g$-SAN2 is obviously stronger than those of POE- $g$-SAN1, which is due to their different grating ratios. GR of POE- $g$-SAN2 is higher than that of POE- $g$-SAN1, so the characteristic peaks of former is stronger than those of the latter.

Figure 7(a), 7(b) gives the ${ }^{1} \mathrm{H}$ NMR spectra of the pure POE and the POE- $g$-SAN, respectively. For pure POE, it can be seen from Figure 7(a) that only the functional groups of POE: $1\left(-\mathrm{CH}_{3}\right), 2\left(-\mathrm{CH}_{2}-\right)$, and $3(-\mathrm{CH}-)$ appear at $0.8-1.0$, 1.1-1.3, and 1.4-1.6 ppm, respectively. The ${ }^{1} \mathrm{H}$ NMR spectrum of POE- $g$-SAN shows that some peaks occur at 4 $(\delta: 1.8-2.0 \mathrm{ppm}), 5$ and $6(\delta: 2.8-3.0 \mathrm{ppm})$, and 7 ( $\delta: 7.0-7.4$ ppm) in addition to the original peaks of POE. The appearances of peaks 4, 5, 6 and 7 are due to St-An grafted onto POE.

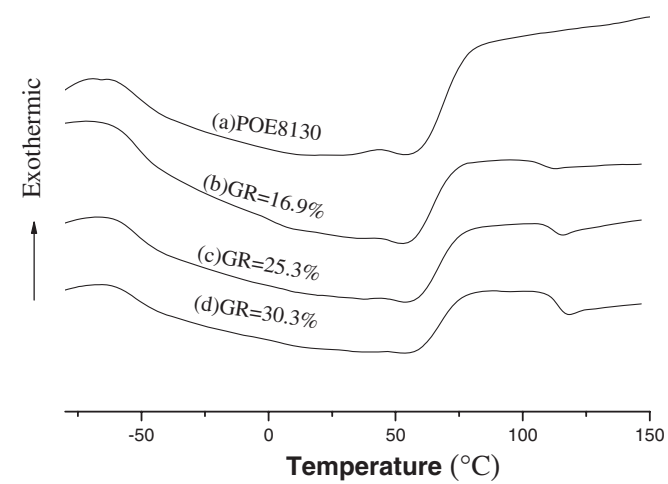

Figure 8. DSC heating thermograms of POE and POE-g-SAN with different GR.

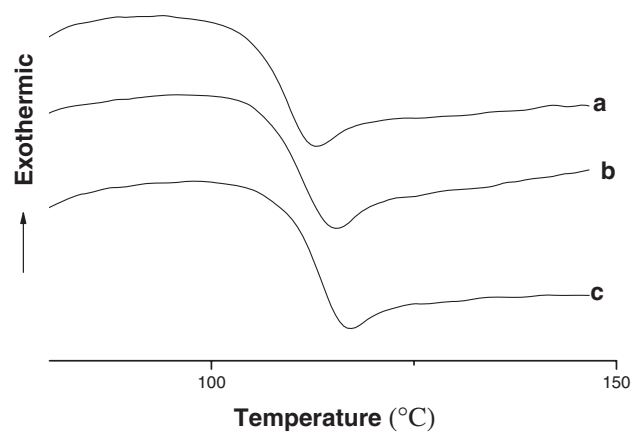

Figure 9. DSC heating thermograms of POE- $g$-SAN copolymer with different St/An ratio, (a) POE- $g$-SAN St $/ A n=70 / 30$; (b) POE- $g$-SAN $\mathrm{St} / \mathrm{An}=60 / 40$; (c) POE- $g$-SAN St/An $=50 / 50$.

\section{Different Scanning Calorimetry Test}

DSC was used to understand the effects of weight ratios of monomers and GR on the thermal properties of POE- $g$-SAN copolymer. The DSC heating thermograms of POE- $g$-SAN with different $\mathrm{POE} / \mathrm{M}$ and $\mathrm{St} / \mathrm{An}$ ratios are shown in Figure 8 and Figure 9, respectively. Figure 8 showed that there are a glass transition and a melt peak in the the DSC heating thermograms of pure POE ranging from -50 to $150{ }^{\circ} \mathrm{C}$. However there are two glass transition and a melt peak in the DSC heating thermograms of POE- $g$-SAN in the same temperature range. It can be considered that the new glass transition of POE- $g$-SAN is due to the segment movement of the graft SAN chains. The temperature of glass transition $\left(T_{\mathrm{g}}\right)$, melting temperatures $\left(T_{\mathrm{m}}\right)$ and the heat of fusion $\left(\Delta \mathrm{H}_{\mathrm{f}}\right)$ of POE- $g$-SAN are lower than that of pure POE. Table II showed the effect of GR on the value of $T_{\mathrm{m}}, \Delta \mathrm{H}_{\mathrm{f}}$ and $T_{\mathrm{g}}$. It is apparent that $T_{\mathrm{m}}$ and $\Delta \mathrm{H}_{\mathrm{f}}$ decreased with an increasing of GR, which is due to the grating SAN chains that disrupted the regularity of the chain

Table II. The $T_{\mathrm{m}}, \Delta \mathrm{H}_{\mathrm{f}}$ and $T_{\mathrm{g}}$ of POE and POE-g-SAN with different GR

\begin{tabular}{cccc}
\hline Grafting Ratios $(\%)$ & $T_{\mathrm{m}}\left({ }^{\circ} \mathrm{C}\right)$ & $\Delta \mathrm{H}_{\mathrm{f}}(\mathrm{J} / \mathrm{g})$ & $T_{\mathrm{g}}\left({ }^{\circ} \mathrm{C}\right)$ \\
\hline 0 & 53.8 & 4.9 & -54.9 \\
16.9 & 52.3 & 4.6 & -53.6 \\
25.3 & 50.9 & 3.4 & -52.7 \\
30.3 & 50.7 & 3.2 & -51.7 \\
\hline
\end{tabular}




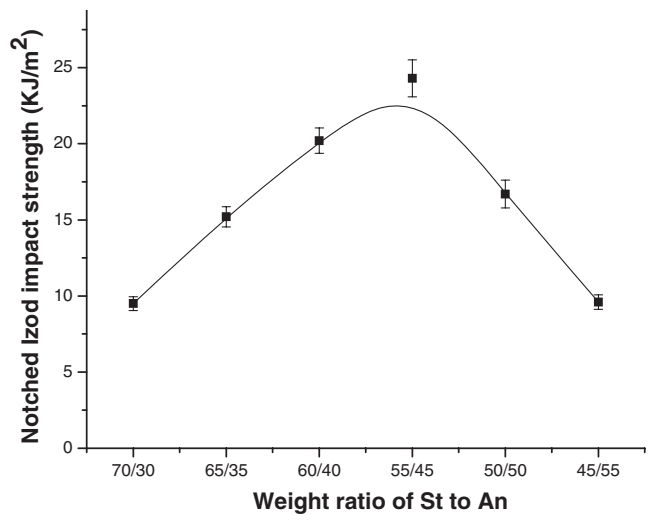

Figure 10. Effect of St/An on notched izod impact strength of SAN/POE- $g$ SAN blends (content of POE $=25 \%$ ).

structures in POE and increased the spacing between the chains. $^{25}$ The $T_{\mathrm{g}}$ of POE phase increased with increasing of GR. It is probably caused by the increase in difficulty in polymer chain arrangements as the grafted branch chains prohibit the movements of the polymer segments.

Figure 9 shows $T_{\mathrm{g}}$ of graft SAN chains of POE- $g$-SAN with different weight ratio of St/An. It was determined that the $T_{\mathrm{g}}$ with increasing An loading is $108.1,110.0$, and $112.5^{\circ} \mathrm{C}$.

\section{Effect of St/An Feed Ratio on the Mechanical Properties}

POE is a kind of non-polar polymer, while SAN resin is polar polymer. Homogenous dispersion of the non-polar POE in polar SAN would not be easy. By modifying POE through grafting polar SAN branches, POE- $g$-SAN can disperse well in SAN matrix. Figure 10 demonstrate the effect of POE- $g$-SAN synthesized with different weight ratio of $\mathrm{St} / \mathrm{An}$ on the Notched Izod impact strength of SAN/POE- $g$-SAN blends, which contained $25.0 \mathrm{wt} \%$ POE. The Notched Izod impact strength of SAN/POE- $g$-SAN blends increased with an increasing of An percentage, and up to $24.3 \mathrm{KJ} / \mathrm{m}^{2}$ at $55 / 45$. However, with further increasing of An percentage the Notched Izod impact strength of SAN/POE- $g$-SAN blends decreased. This can be explained by the fact that the polarity of grafting SAN branches increased with the decreasing weight ratio of St/ An. The polarity of An is higher than that of St. Consequently when the percentage of An increased with the decreasing weight ratio of St/An, the polarity of grafting SAN branches increased. When the polarity value of grafting SAN branches is in some certain range, POE- $g$-SAN can dispersed well in SAN matrix, and can improve the impact resistance of SAN resin.

\section{Effect of Grating Ratio on the Mechanical Properties}

Figure 11 shows the effect of POE-g-SAN with different grafting ratios on the Notched Izod impact strength of the SAN/POE- $g$-SAN blend. The Notched Izod impact strength increased with an increasing grafting ratio, and got a peak at $28.5 \%$. POE- $g$-SAN with a low grafting ratio have few grafting SAN branches. Hence, by toughing of SAN with POE- $g$-SAN with a low grafting ratio it is difficult to achieve appropriate

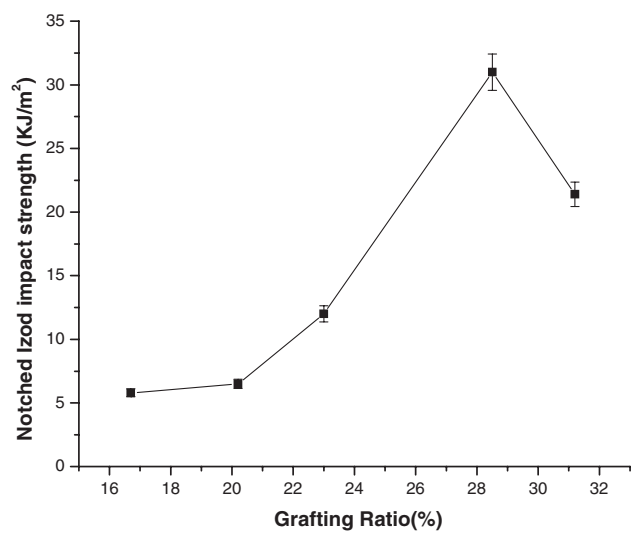

Figure 11. Effect of grating ratio of POE- $g$-SAN on the notched izod impact strength of POE/SAN blends.

compatibility. With the increasing grafting ratio, POE-g-SAN have more grafting SAN branches on the backbone, which make it achieve appropriate compatibility when blend with SAN resin. POE- $g$-SAN dispersed in the matrix at a optimum dimension and result in an increasing Notched Izod impact strength. However, when the grafting ratio of POE-g-SAN increased higher than about $30.0 \%$, the Notched Izod impact strength did not increase anymore. A similar result had been reported by Wang X.D et al., ${ }^{12}$ which showed that further increasing of graft ratio of $\mathrm{MA}$ result in a decrease of the impact strength of PPO/PA6/POE- $g$-MA blend.

\section{Effect of POE Content on the Mechanical Properties}

Figure 12 shows the effect of POE content on the Notched Izod impact strength and tensile strength of SAN/POE- $g$-SAN blends. The Notched Izod impact strength of pure SAN is $0.9 \mathrm{KJ} / \mathrm{m}^{2}$. The toughness was very poor. The Notched Izod impact strength increases slowly with the increasing POE content from 0 to $15 \mathrm{wt} \%$. When the POE content is more than 15 wt $\%$, the Notched Izod impact strength increases dramatically with increasing POE content, and gets $34.5 \mathrm{KJ} / \mathrm{m}^{2}$ at

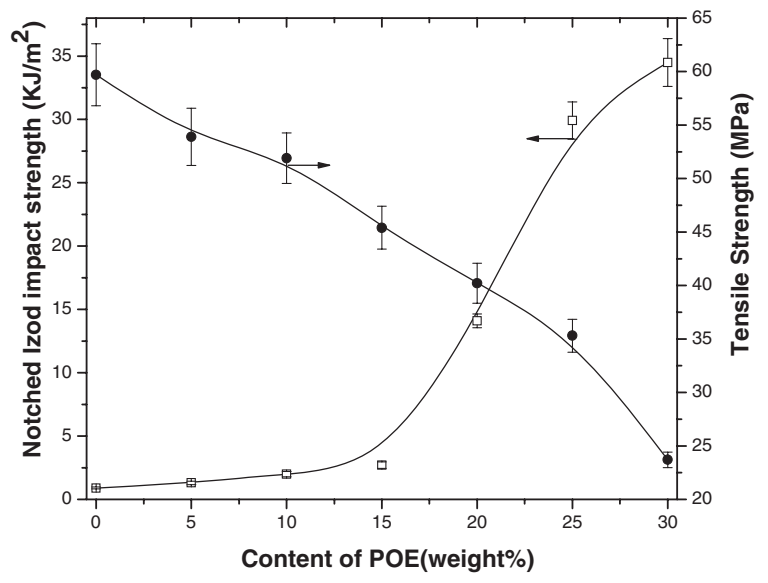

Figure 12. Content of $\mathrm{POE}$ on notched izod impact strength and tensile strength of POE/SAN. 


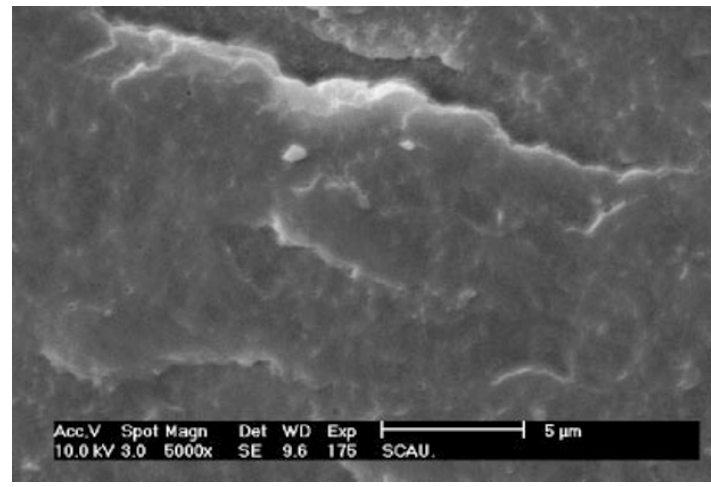

(a)



(c)

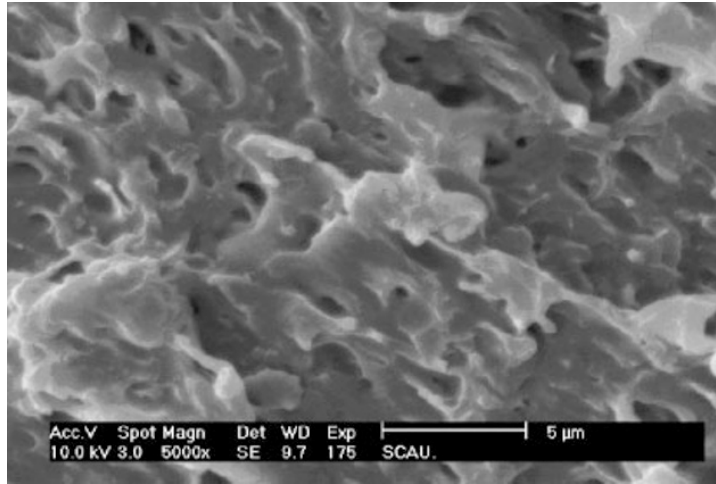

(b)

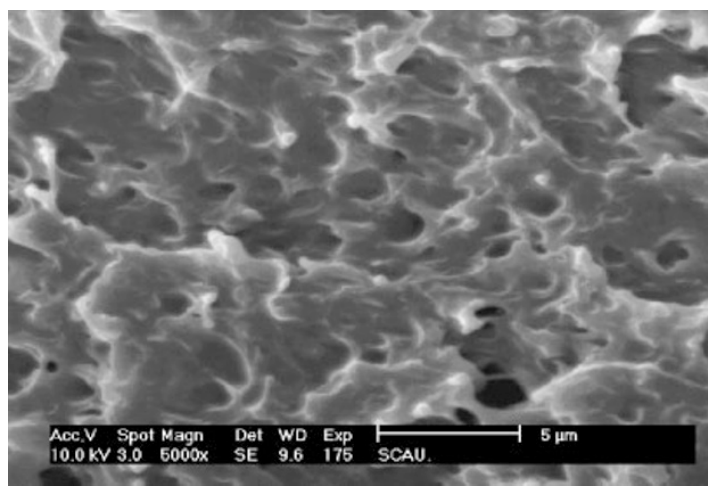

(d)

Figure 13. SEM photos for SAN/POE- $g$-SAN blends: (a) POE content $=10 \%$; (b) POE content $=25 \%$; (c) POE- $g$-SAN with grafting ratio of $23.0 \%$, POE content $=25 \%$; (d) POE- $g$-SAN with grafting ratio of $28.5 \%$, POE content $=25 \%$.

$30 \mathrm{wt} \%$. When the POE content of the blend is between 15 and $20 \mathrm{wt} \%$, a sharp brittle-to-tough transition is observed upon variation of POE content. The increase in impact strength is, however, at the expense of tensile strength. The tensile strength of SAN/POE- $g$-SAN blends, as shown in Figure 12, decreased almost linearly with increasing POE content. These results are generally found in various blends and have been reported to be due to the softening or diluting effect of the incorporation of a soft elastomeric phase to the matrix. ${ }^{26}$

\section{Scanning Electron Microscopy}

Figure 13(a) and 13(b) show the influence of POE content on the morphology of the SAN/POE- $g$-SAN blend. It is clear seen that there are no bare POE drops on the fracture surface, indicating that POE- $g$-SAN disperse well in the blend. Figure 13(a) shows that the fracture surface is plane with some crack and limited cavitation of rubber particles. This means that its Notched Izod impact strength would not be much improved. Figure 13(b) shows the fracture surface with $25 \%$ POE, which results in extensive cavitation and matrix shear yielding. Such cavitation and matrix shear yielding lead to a large amount of plastic deformation, thereby dissipating a significant amount of impact energy. Figure 13(c) and 13(d) show the influence of GR of POE- $g$-SAN on the morphology of the SAN/POE- $g$-SAN blend. The addition of POE- $g$-SAN with GR of $23.0 \%$ to SAN [Figure 13(c)] showed cavitation. However, there are not obvious matrix shear yielding. Adding POE- $g$-SAN with GR of $28.5 \%$ [Figure 13(d)] results in cavitation and matrix shear yielding. Thus the blend containing POE- $g$-SAN with grating ratio of $28.5 \%$ showed higher impact strength than that containing POE- $g$-SAN with grating ratio of $23.0 \%$.

\section{CONCLUSION}

Graft copolymerization of $\mathrm{St}$ and An onto POE was investigated in this article. The reaction variables, such as weight ratios of St to An, weight ratio of POE to monomers, reactant concentration, initiator concentration, and reaction time, significantly affect $\mathrm{CR}$, GR, and GE of the graft copolymerization. According to FT/IR and ${ }^{1} \mathrm{H}$ NMR, it was confirmed that $\mathrm{St}$ and An is essentially grafted onto POE. From the result of DSC, it was found that the values of $T_{\mathrm{m}}$ and $\Delta \mathrm{H}_{\mathrm{f}}$ decreased as the graft ratio increasing, and $T_{\mathrm{g}}$ of POE chain increased with an increasing GR. It was also seen that the value of $T_{\mathrm{g}}$ of graft SAN chain increased with the increasing of An percentage. SEM micrographs show the good miscibility of POE/SAN- $g$-SAN blends and POE- $g$-SAN proved to be an 
effective toughening agent for SAN. When POE content of the blend reaches $15 \mathrm{wt} \%$, a sharp brittleto-tough transition will occur. The toughening mechanism is considered to be the crazing initiation from rubber particles and shear deformation of the SAN resin.

Received: October 25, 2007

Accepted: February 22, 2008

Published: April 16, 2008

\section{REFERENCES}

1. P. S. Chun, C. I. Kao, and G. W. Knight, Plast Eng., 21, (1995).

2. A. L. N. Da. Silva, M. I. B. Tavares, D. P. Politano, F. M. B. Coutinho, and M. C. G. Rocha, J. Appl. Polym. Sci., 66, 2005 (1997).

3. J. Chen, W. Yang, Z. Y. Liu, and R. Huang, J. Mater. Sci., 39, 4049 (2004).

4. H. T. Chiu and Y. K. Hsiao, J. Polym. Res., 12, 355 (2005).

5. Z. Z. Yu, Y. C. Ke, Y. C. Ou, and G. H. Hu, J. Appl. Polym. Sci., 76, $1285(2000)$.

6. Z. Z. Yu, Y. C. Ke, Y. C. Ou, and G. H. Hu, J. Appl. Polym. Sci., 69, 1711 (1998).

7. Q. F. Li, D. G. Kim, D. Z. Wu, K. Lu, and R. G. Jin, Polym. Eng. Sci., 41, 2155 (2001).

8. H. T. Chiu and Y. K. Hsiao, J. Polym. Res., 13, 153 (2006).

9. S. L. Bai, G. T. Wang, J. M. Hiver, and C. G'Sell, Polymer, 45, 3063 (2004).
10. S. L. Bai, J. M. Hiver, and C. G'Sell, Polymer, 45, 5785 (2004).

11. S. L. Bai, C. G'Sell, J. M. Hiver, and C. Mathieu, Polymer, 46, 6437 (2005).

12. X. D. Wang, W. Feng, H. Q. Li, and R. Jin, J. Appl. Polym. Sci., 88, $3110(2003)$

13. W. X. Zhong, X. Y. Qiao, K. Sun, G. D. Zhang, and X. D. Chen, J. Appl. Polym. Sci., 99, 2558 (2006).

14. Z. Li, S. Y. Guo, W. T. Song, and B. Hou, J. Mater. Sci., 38, 1793 (2003).

15. H. T. Chiu and Y. K. Hsiao, Polym. Eng. Sci., 44, 2340 (2004).

16. S. M. Lai, Y. C. Liao, and T. W. Chen, J. Appl. Polym. Sci., 100, 1364 (2006).

17. C. S. Wu, S. M. Lai, and H. T. Liao, J. Appl. Polym. Sci., 85, 2905 (2002).

18. C. S. Wu, J. Polym. Sci., Part A: Polym. Chem., 41, 3882 (2003).

19. M. F. Lu, S. J. Zhang, and D. S. Yu, J. Appl. Polym. Sci., 93, 412 (2004).

20. C. M. Jiao, Z. Z. Wang, Z. Gui, and Y. Hu, Eur. Polym. J., 41, 1204 (2005).

21. P. He, H. Huang, Y. Zhang, and N. C. Liu, React. Funct. Polym., 62, 25 (2005).

22. G. Odian, "Principle of Polymerization," 4th ed., New Jersey, John Wiley \& Sons, Inc, 2004.

23. P. Ghosh, B. Chattopadhyay, and A. K. Sen, Polymer, 39, 193 (1998).

24. S. N. Sathe, G. S. S. Rao, and S. Devi, J. Appl. Polym. Sci., 53, 239 (1994).

25. T. M. Ko and P. Ming, Polym. Eng. Sci., 40, 1589 (2000).

26. Z. P. Zeng, L. S. Wang, T. M. Cai, and X. Zeng, J. Appl. Polym. Sci., 94, 416 (2004). 